\title{
A PRODUÇÃO IMAGINÁRIA NA ESCOLA E A FORMAÇÃO DE PESSOAS CRIADORAS: REFLEXÕES A PARTIR DA TEORIA HISTÓRICO-CULTURAL
}

\section{THE IMAGINARY PRODUCTION IN THE SCHOOL AND THE TRAINING OF CREATIVE PEOPLE: REFLECTIONS FROM THE HISTORICAL-CULTURAL THEORY}

\section{LA PRODUCCIÓN IMAGINARIA EN LA ESCUELA Y LA FORMACIÓN DE PERSONAS CREADORAS: REFLEXIONES A PARTIR DE LA TEORÍA HISTÓRICO-CULTURAL}

Solange Maria Alves ${ }^{1}$

Resumo: Este texto materializa um conjunto de reflexões decorrentes do processo de investigação, estudos e discussões que tem o imaginário criativo e a formação de pessoas criadoras na perspectiva histórico-cultural, como objeto principal. Nos parâmetros deste artigo, nos limitamos a contribuir para o debate da temática em tela, trazendo alguns elementos da base teórica do materialismo histórico-dialético, fundamento da teoria histórico-cultural, mais especificamente a categoria de trabalho social em Marx, como parte da atividade vital constitutiva do gênero e a tese vigotskiana sobre a origem cultural das funções superiores de pensamento, incluídas a imaginação e a criação neste escopo, para, a partir daí, articulando alguns pressupostos de Lev. S. Vigotski sobre imaginação e criação, tecer considerações que ajudem a construir tempos e espaços escolares focados no desenvolvimento humano tal como concebido pela psicologia marxista. Sem pretender dar conta da complexidade inerente ao tema, a intenção é que, somado a outros estudos e contribuições, este texto seja mais um provocador de novas imagens e criações sobre a formação de pessoas criadoras como tarefa da educação escolar.

Palavras-chave: Imaginário Criativo e Formação de pessoas criadoras. Desenvolvimento humano e educação. Teoria histórico-cultural.

Abstract: This text materializes a set of reflections resulting from the process of research, studies and discussions that has the creative imaginary and the formation of creators people in the culturalhistorical perspective, as main object. In the parameters of this paper, the objetive is to contribute to the debate on the topic presented, including some elements arise from the theoretical basis of

\footnotetext{
${ }^{1}$ Universidade Federal da Fronteira Sul -UFFS. Chapecó, Santa Catarina, Brasil.
} 
dialectical and historical materialism, base of the cultural-historical theory, more specifically the category of social work in Marx, as part of the vital activity constitutive of the genre and the Vygotsky's thesis about the cultural origin of the higher mental functions, including the imagination and the creation in this scope, and from this, articulating some of Vygotsky's presuppositions about imagination and creation, to make considerations that help to build times and school spaces focused on human development as designed by Marxist psychology. Without an intention of cover all the complexity inherent to the theme, the purpose is, in addition of other studies and contributions, that this text be one more provocative of the new images and creations on the formation of creative people as a school education task.

Keywords: Creative Imaginary and Creation of creative people. Human development and education. Cultural-Historical theory.

Resumen: Este texto materializa un conjunto de reflexiones resultantes del proceso de investigación, estudios y discusiones que tienen el imaginario creativo y la formación de personas creadoras en la perspectiva histórico-cultural, como objeto principal. En los parámetros de este artículo, nos limitamos a contribuir para el debate de la presente temática, trayendo algunos elementos de la base teórica del materialismo histórico-dialéctico, fundamento de la teoría histórico-cultural, más específicamente la categoría del trabajo social en Marx, como parte de la actividad vital constitutiva del género y la tesis vigotskiana sobre el origen cultural de las funciones superiores del pensamiento, incluidas la imaginación y la creación en este sentido, para, a partir de ahí, articulando algunos presupuestos de Lev. S. Vigotsky sobre imaginación y creación, tejer consideraciones que ayuden a construir tiempos y espacios escolares enfocados en el desarrollo humano tal como concebido por la psicología marxista. Sin pretender dar cuenta de la complejidad inherente al tema, la intención es que, sumado a otros estudios y contribuciones, este texto sea más un provocador de nuevas imágenes y creaciones sobre la formación de personas creadoras como tarea de la educación escolar.

Palabras-clave: Imaginario Creativo e Formación de personas creadora. Desarrollo humano y educación. Teoría histórico-cultural.

\section{Introdução}

Em que pese vivermos num mundo de comunicação instantânea, ele mesmo fruto de invenções (portanto da imaginação, criação humana), que, por sua vez, modifica as formas de organização e funcionamento do pensamento, da cognição, o tema do imaginário criativo, da criação como possibilidade de novos arranjos pedagógicos, parece ser ainda algo desconhecido. Via de regra, o termo imaginação está vinculado à fantasia, elaborações mentais irreais, coisas que se dão ao sujeito magicamente, como algo que se tem ou não se tem desde o nascimento, entre outros, e não como um ato de pensamento que se realiza pelo sujeito, ao mesmo tempo em que o constitui como gênero humano. A ausência dessa reflexão na pauta das ações educativas escolares 
pode, entre outras importantes questões, justificar o mecanicismo escolar, a repetição mecânica de códigos e de situações pedagógicas que, em última análise, constituem o fundamento do fracasso escolar.

Na contramão dessa concepção, a reflexão em tela, fruto de aprofundamentos e reflexões construídas em torno do tema do imaginário criativo e educação escolar como objeto de pesquisa, propõe a leitura e a compreensão do tema em bases teóricas e metodológicas do campo do materialismo histórico-dialético. À luz desse referencial, estamos diante de um tempo novo, altamente dinâmico, rápido, produto do trabalho criador do ser humano. Modifica-se a base técnica de produção, modificam-se as relações de trabalho. Mudanças decorrentes do trabalho humano que, a um só tempo, transformam o mundo, o entorno, a natureza e o humano, como já nos ensinou (MARX, 2003) ao afirmar que os homens transformam a natureza e a natureza transformada, transforma o próprio homem.

Nesta perspectiva, o trabalho como atividade teleológica, voltada para um fim específico, é um ato que exige do psiquismo a função imaginária. Ou seja, o ser humano, por meio da atividade do trabalho, gera nele mesmo uma nova demanda: a de antecipar idealmente o que fazer, para que fazer, com que fazer. Logo, a atividade vital humana passa a ser orientada por um projeto, no que reside a origem da imaginação como função psíquica criadora, a um só tempo, dos objetos (tecnologias, inovações, relações, organizações) que carregam a subjetividade de quem os criou, e do humano que se cria, se objetiva e complexifica pela sua própria criação.

Coerente com os pressupostos do materialismo histórico-dialético, nos apoiamos também, para esta reflexão, na tese da origem cultural das funções superiores de pensamento de Lev. S. Vigotski e colaboradores filiados à teoria histórico-cultural do desenvolvimento humano. Neste âmbito, o imaginário criativo é concebido como função psicológica superior cuja origem está associada ao trabalho como parte fundamental da atividade vital do gênero humano. Logo, pensar a imaginação e a criação implica pensar o humano concreto e para além dos imediatismos da racionalidade liberal hegemônica.

Cabe dizer ainda que, embora esse eixo temático de que estamos falando surja no campo da psicologia, mais especificamente da corrente histórico-cultural de psicologia, ele tem importantes implicações em diferentes campos da atividade social e tecnológica. Aqui, nos interessa de modo particular, suas implicações no campo da Educação: i.) em geral, entendida como o processo social e cultural da constituição humana do homem, ii.) da educação escolar, entendida como parte integrante da educação em geral, enquanto uma dimensão particular desse processo. Com efeito, 
a educação escolar ou formal passou a constituir, na modernidade, a via de acesso ao conhecimento científico, ou seja, ao saber que os homens têm do mundo natural como resultado e condição da sua transformação pelo trabalho. Não é a única via, mas é a socialmente instituída e como tal, constitui foco de investigações, problematizações e estudos importantes. Entre eles o que se constitui foco e escopo da reflexão aqui empreendida, que é parte dos fundamentos teóricos de pesquisa ocupada com a temática da atividade criadora e do imaginário criativo desde a organização pedagógica na educação básica aos processos formativos no âmbito da formação inicial e continuada de professores.

Alicerçada na teoria histórico-cultural de desenvolvimento humano, a pesquisa que dá origem ao texto em tela, tem como pressuposto fundamental a crença de que a escola e a educação escolar constitui-se espaço-tempo de desenvolvimento do imaginário criativo, como função superior de pensamento. É, por isso, arena privilegiada de desenvolvimento de pessoas criadoras e, por consequência, do gênero humano.

Sem pretender dar conta da complexidade do tema, esta reflexão se soma a outros estudos, como os de Artur Bruno Fonseca de Oliveira e Ana Ignez Belém Lima (2017), Geisa Nunes de Souza Mozzer e Fabrícia Teixeira Borges (2008), Andréa Vieira Zanella, Angel Pino, Susana Inês Molon, Katia Maheiri, Luciane Maria Schlindwein, (2006), entre outros importantes educadores comprometidos e ocupados com a temática do imaginário criativo e educação escolar na perspectiva da teoria histórico-cultural de desenvolvimento humano, e se coloca para contribuir com processos educacionais dispostos à uma práxis pedagógica intencionalmente focada no desenvolvimento humano que inclui a imaginação e a formação de pessoas criadoras.

\section{Imaginário criativo: aspectos teóricos fundamentais para uma outra escola possível}

O imaginário é o que define a condição humana do homem. Angel Pino

Duas razões estão na gênese do que justifica a realização deste estudo. Uma, de natureza sociocultural, refere-se a ausência, nos currículos escolares, tanto de princípios pedagógicos quanto de atividades voltadas para a formação de pessoas criadoras, o que, a nosso ver, contribui largamente para os baixos índices de aproveitamento escolar e, na vida profissional, a baixa capacidade de adaptação às mudanças que a revolução tecnológica provoca nas condições de 
produção. Outra, de natureza científica, traduz-se na intenção de estudar, no campo da educação escolar, a aplicabilidade da tese da natureza cultural do ser humano que faz dele um ser criador. (VIGOTSKI, 1995).

Do ponto de vista teórico, a reflexão sobre o processo criativo aqui empreendida, tem como suporte epistemológico o estudo de outro grande tema teórico-prático: o conceito de atividade criadora na linha do modelo do trabalho social de Marx. A obra de Lev S. Vigotski, que tem como matriz principal de referência o materialismo histórico- dialético de Marx e Engels, constitui, no âmbito desta reflexão e dos estudos que vimos realizando, a principal via de articulação e fundamento da análise que busca, entre outros aspectos, conceber a imaginação, a criação, como elementos constitutivos do humano em nós e, desde a teoria histórico-cultural de Vigostki e colaboradores, compreendidas como funções psicológicas superiores, ou funções superiores de pensamento vinculadas a formas mais complexas de cognição, volição e afeto. Importante destacar que, para a teoria histórico-cultural, a cisão cognição e afeto não só é indesejável como inexistente. Para este campo teórico, o humano é constituído da concreticidade das relações sociais. O que diz respeito á sua integralidade, totalidade como individualidade histórica, feito pelas mediações simbólicas, semióticas, isto é, de significados e sentidos produzidos no âmbito das relações sociais que são, por sua vez, históricas e culturais. Sem desconsiderar as bases orgânicas sobre as quais as emoções humanas se desenvolvem, Lev S. Vigotski vê na linguagem - sistema simbólico básico de todos os grupos humanos -, os elementos fundamentais para compreender as origens do psiquismo. Para ele a forma de pensar inclui também os sentimentos. Pensar e sentir são, portanto, ações indissociáveis.

Assim, a parte inicial do enunciado do título deste texto se insere num dos eixos temáticos advindos de reflexões teóricas sobre algumas das grandes contribuições da psicologia históricocultural (Lev S. Vigotski e colaboradores) à compreensão da natureza humana que permite estabelecer uma ligação fundamental entre a atividade imaginária e a produção cultural do homem. Eixo fundado em duas grandes teses: a do trabalho social de Marx (MARX, 1972, 1986) e (MARX e ENGELS,1993) e a da origem das funções superiores ou culturais de Lev S. Vigotski (VIGOTSKI, 1995). Em relação à primeira tese, tal como dito por Pino (2006), o conceito de "trabalho social" de Marx - entendido como atividade do trabalhador ou como produto dessa atividade - tem dois sentidos opostos e aparentemente contraditórios. Um decorre das análises que ele faz da "economia política" (expressão empregada por ele) nas sociedades que vivem historicamente sob o regime da 
propriedade privada dos meios de produção. Nestas condições históricas, o trabalho tem para Marx um significado negativo enquanto atividade alienada e alienante do trabalhador. Este tipo de análise aparece principalmente nos Manuscritos de 1944, mas está presente também em outras obras posteriores. No fim do primeiro manuscrito, o autor se refere claramente ao trabalho alienado, diz ele:

Partindo da própria economia política, utilizando seus próprios termos, mostramos que o operário é rebaixado ao nível de mercadoria, e da mais miserável mercadoria, que a miséria do operário está em razão inversa ao poder e à grandeza da sua produção. [...] O trabalho não produz apenas mercadorias; ele se produz a si mesmo e produz o operário enquanto mercadoria [...]. Este fato nada mais expressa que isto: o objeto que o trabalho (do operário) produz, seu produto, o confronta como um ser estrangeiro, como uma potência independente do produtor. [...]No estágio da economia, esta atualização do trabalho aparece como a perda por parte do operário da sua realidade, a objetivação como a perda do objeto ou a subserviência a ele, a apropriação como a alienação, a desapropriação [...] A tal ponto a apropriação do objeto se revela uma alienação que quanto mais objetos o operário produz, menos ele pode possuir e mais ele cai sob a dominação do seu produto. (MARX, 1972, p.57)

Até aqui só consideramos a alienação, a desapropriação do operário sob um único aspecto, aquele da sua relação com os produtos do seu trabalho. O outro sentido a que nos reportamos acima, decorre da análise filosófica do trabalho humano que Marx apresenta no capítulo VII de $O$ Capital e que serve de fundamento ao conceito de trabalho considerado aqui o modelo para pensar a atividade criadora humana. Eis as palavras de Marx:

O trabalho é, antes de tudo, um ato que se passa entre o homem e a natureza. O próprio
homem desempenha aí frente à natureza o papel de uma potência natural. As forças de que
o seu corpo é dotado, braços e pernas, cabeça e mãos, ele as põe em movimento a fim de
assimilar-se matérias dando-lhes uma forma útil para sua vida. Ao mesmo tempo em que
por este movimento ele age sobre a natureza exterior e a modifica, modifica sua própria
natureza e desenvolve as faculdades adormecidas nela. Nós não nos deteremos neste
estado primordial do trabalho, em que ele ainda não eliminou seu caráter puramente
instintivo. Nosso ponto de partida é o trabalho sob uma forma que pertence
exclusivamente ao homem [...] O resultado a que chega o trabalho pré-existe idealmente
na imaginação do trabalhador. Não é que ele opere somente uma mudança de forma nas
matérias naturais; ele realiza ao mesmo tempo seu próprio objetivo, do que ele tem
consciência, o qual determina como uma lei seu modo de ação e ao qual ele deve subordinar
sua vontade. (MARX, 1986, p. 136) (grifo nosso) Duas ideias importantes a respeito da natureza do trabalho social decorrem dessas palavras de Marx. A primeira é que, ao agir sobre a natureza exterior e transformá-la, o homem transforma sua própria natureza e desenvolve as faculdades adormecidas nela. Isso quer dizer que com o trabalho o homem confere à Natureza uma nova forma de existência, a existência cultural e, pelo mesmo ato, transforma sua natureza "natural" ou biológica numa natureza humana, obra de si mesmo. A segunda é que com o trabalho o trabalhador realiza seu próprio objetivo do qual ele tem 
consciência, pois o resultado a que ele chega, como diz Marx "pré-existe idealmente na sua imaginação". Em outras palavras, na medida em o trabalho é uma atividade plenamente humana o que não ocorre no trabalho alienado e alienante -, o trabalhador sabe o que ele quer realizar e os meios que deve utilizar para atingir o objetivo que ele se propõe. Esse saber prévio do que ele quer fazer, do modo de fazer e dos meios necessários para chegar ao seu objetivo constitui o que denominamos de projeto que, fundamentalmente, é uma criação imaginária do que poderá tornarse uma realidade em si ou concreta. É esse projeto que orienta o conjunto da sua atividade de trabalho e o produto final que, ao objetivar-se permite ao trabalhador avaliar a relação entre o produto alcançado e o projeto que imaginou.

Se é relativamente fácil compreender essas duas teses no seu sentido geral, ou seja, aplicado à história da espécie humana como um todo, não é tão fácil compreendê-las quando aplicadas à história particular dos indivíduos singulares. Em primeiro lugar, o conceito de trabalho, tal como aparece na tese geral, tem uma conotação específica dada pelo contexto da análise do processo de produção econômica em que Marx o utiliza e que lhe permite fazer a crítica do modo de produção capitalista. Fora desse contexto, entretanto, ele conserva toda sua força, se entendido como definidor da especificidade da atividade humana, qualquer que ela seja. Isso não quer dizer que sejam concepções diferentes, mas que o conceito de trabalho se situaria dentro do conceito mais amplo de atividade humana que, para ser humana, deve reunir as características atribuídas ao trabalho. Ou seja, precisa ser atividade intencional, objetivada, projetada, imaginada. Neste sentido, fica inviável compreender a atividade humana desconectada da consciência. Ambas compõem, por assim dizer, uma relação de funcionalidade dialética onde a consciência é uma forma tipicamente humana de reflexo psíquica da realidade. O que quer dizer que ela expressa as relações dos indivíduos na complexa rede social em que se encontram, lugares sociais, culturais, historicamente produzidos.

Em segundo lugar a tese de Marx explica o desenvolvimento histórico do homem e do seu mundo em geral, não o do homem singular no interior dele, não obstante o fato que o trabalho é social não porque o sujeito seja um grande coletivo identificado com a espécie humana, uma vez que ele, por definição, seria a atividade de sujeitos singulares. Entretanto, o trabalho social de Marx, embora vise singularidades, é conceituado como um processo histórico de produção que ocorre no complexo meio das relações sociais em que determinados segmentos sociais se apropriam dos meios de produção e com eles dos meios de acesso aos produtos culturais decorrentes da atividade 
produtiva e, esse processo, determina a maneira como ocorre a relação dos indivíduos com a Natureza, como reza o conceito de trabalho humano a que se refere Marx nas suas teses filosóficas. Trata-se, pois, de duas dimensões de um mesmo e único processo histórico. O que significa que o caráter produtivo da atividade humana opera nos dois polos de que é a mediadora: na natureza, transformando-a em cultura ou obras do Homem; e no homem, transformando-o pela cultura.

Em relação à tese de Lev S. Vigotski sobre a origem das funções superiores, ou culturais, ocorre algo parecido ao que ocorre com o conceito de trabalho social. É relativamente fácil entender a tese enquanto princípio geral que diz respeito ao processo de filogênese da espécie humana. Ela revela que dentre as espécies homo, alguma especificamente, passou por um processo histórico de evolução biológica que a distanciou das outras pelo aparecimento de características novas próprias que deram origem à emergência da(s) espécie(s) humana(s). Não é tão fácil, porém, entender essa tese se aplicada às singularidades dos indivíduos que constituem essa(s) espécie(s) ao longo da evolução.

À semelhança do que ocorre com a tese do trabalho social de Marx, a tese de Lev S. Vigotski sobre a origem das funções superiores ou culturais pressupõe que, sem a emergência dessas funções em cada um dos indivíduos que integram a(s) espécie(s) humana(s), não haveria funções novas. Mas, por outro lado, sem a emergência inicial dessas funções no sujeito coletivo (tribo, grupo, sociedade) não haveria emergência nos indivíduos singulares, pela simples razão de que se trata de um processo evolutivo em que as sucessivas gerações que se sucedem no tempo e no espaço históricos, tornam-se herdeiros dos avanços evolutivos, tanto culturais como biológicos por eles afetados, do sujeito coletivo. É num mundo social e culturalmente evoluído que as novas gerações encontram as condições da própria evolução. Uma coisa parece certa, o sujeito coletivo e os sujeitos singulares que o integram formam um complexo tecido de relações dialéticas em que o todo e as partes formam uma unidade que se autoconstitui.

No fim destas colocações iniciais impõe-se a indagação: que relação pode existir entre a tese do trabalho social de Marx e a tese da origem das funções superiores de Lev S. Vigotski? Por estranho que possa parecer, sem a tese do trabalho social que tenta explicar, ao mesmo tempo, a origem material $\mathrm{da}(\mathrm{s})$ espécie(s) humana(s) que se transforma(m) ao agir sobre a Natureza e, ao transformá-la, criam suas próprias condições de existência, não teríamos como explicar a emergência da(s) espécie(s) humana(s). Uma vez que para passar do estado de Natureza, aquele das funções biológicas herdadas das diferentes espécies que a(s) precedera(m) na sua evolução, 
torna-se necessária a existência de um acontecimento novo para além da mera evolução biológica. Esse acontecimento novo é a emergência, nas funções biológicas naturais, de outro tipo de funções que não existiam na Natureza. E esse tipo novo de funções é obra do trabalho social que transforma, como já foi dito anteriormente, a natureza em cultura pelo trabalho, e o humano pela produção de cultura.

Quando dizemos que o novo é a emergência de funções complexas sobre as funções naturais, biológicas ou elementares como nomina Lev S. Vigotski (1995), estamos afirmando e corroborando com a convicção do autor e de sua escola, a não separação desses processos psíquicos. Ou seja, não se trata de colocar de um lado os processos biológicos e de outro os culturais, mas de tratá-los como uma unidade dialética donde resulta o desenvolvimento humano, o comportamento, a personalidade. Para este pensador, o comportamento complexo, tipicamente humano, resulta, de um lado, de processos de evolução biológica da espécie homo sapiens onde residem funções psicológicas inatas, herança filogenética, da ordem dos instintos, reflexos e funções de memória biológica e, de outro, um processo de desenvolvimento histórico, fruto do trabalho social como já dito acima, por meio do qual o ser humano primitivo converteu-se em ser cultural, fazendo do espaço-tempo cultural o seu modo de atividade vital, portanto, de reprodução como ser genérico. É neste espaço-tempo da generecidade, da histórica, da cultura humana, que residem os processos funcionais complexos de pensamento ou funções superiores de pensamento, nominadas por: sensação, percepção atenção voluntária, memória mediada, linguagem, pensamento, criação, imaginação, e cuja apropriação se efetiva por meio do emprego e uso de elementos sígnicos amalgamados na linguagem e em processos comunicacionais que funcionam no âmbito psicológico do ser humano, como ferramentas ou instrumentos internos que medeiam a relação do indivíduo com a generecidade humana que o humaniza.

Com base nesse pressuposto teórico, Lev S. Vigotski (2018), desenvolve um conjunto de argumentos importantes acerca da imaginação como função psicológica específica do ser humano. Para este autor, todas as descobertas, maiores ou menores, antes de se efetivarem na prática ou de se consolidarem como invenções, inovações criações humanas importantes, estiveram juntas na imaginação como uma estrutura erigida na mente mediante novas combinações. Sendo o humano resultado de múltiplas sínteses que cada sujeito realiza por meio de mediações sociais, a imaginação e o ato criador resultam do contexto social no qual cada indivíduo se humaniza. 
A temática da atividade criadora está associada aqui à outras duas temáticas: a da "produção imaginária" e a da sua objetivação no produto do trabalho social. A primeira envolve a complexa questão do "imaginário", entendido como a condição de toda possibilidade de produção do homem e como campo de suas produções imaginárias. Pino (2006). E, a segunda, referente a questão da atividade imaginária que, segundo as pistas deixadas por Lev. S. Vigotski (2018), pode ser reprodutora - estreitamente ligada à função da memória - e criadora ou combinatória - responsável pela continuidade do espírito inventivo dos homens -. À luz do método do materialismo históricodialético, este pensador concebe o psiquismo humano como um sistema e não como partes como querem outras concepções acerca do funcionamento cerebral e psíquico. Para ele a atividade psíquica é um complexo articulado. Por isso, as funções superiores de pensamento, de origem e desenvolvimento cultural, produto do trabalho e da linguagem, constituem uma totalidade igualmente complexa. É nesse conjunto articulado que a imaginação e a criação se colocam como funções interligadas a outras como totalidade dialética, ou seja, mesmo como unidade, conserva os elementos de uma totalidade dinâmica, em movimento, como refere o próprio Lev S. Vigotski (1995), quando discute o método de análise do psiquismo humano. Neste sentido, corroboramos com Martins (2013, p.226) ao afirmar que,

[...]A rigor, na abrangência do termo, imaginação designa qualquer processo que se desenvolve por meio de imagens. Portanto, de certo modo, todos os processos funcionais são, em alguma medida, processos imaginativos. Não obstante, como processo funcional específico, a imaginação possui suas singularidades e um curso de desenvolvimento fundamentalmente alinhado ao desenvolvimento da linguagem, do pensamento e dos sentimentos

O que vai nos ajudando a ver, nos limites desta reflexão, de um lado, o imaginário criativo como um complexo interdependente e ao mesmo tempo peculiar, diferente das demais funções, que se efetiva como tal na interrelação com outras funções como percepção, sensação, memória simbólica, atenção voluntária, linguagem, entre outros. De outro, tendo em vista a educação escolar como fator de desenvolvimento dessas funções tipicamente humanas, a complexidade do trabalho educativo para a promoção do imaginário criativo como elemento fundamental de desenvolvimento do gênero humano em cada indivíduo,

Se, como nos lembra Saviani (2003), a tarefa histórica do trabalho educativo é a promoção da humanidade em cada indivíduo, e se para tal tarefa, terá a docência de ser conhecedora de aspectos fundamentais, por um lado, da cultura e de como o humano se tece nas relações sociais concretas e, por outro, da didática no sentido de criar as estratégias pedagógicas mais adequadas a esse desenvolvimento, então, podemos inferir que a formação de pessoas criadoras pela educação 
escolar, implica tanto a construção de relações democráticas no âmbito do processo pedagógico quanto a apropriação dos conhecimentos produzidos pela humanidade ao longo da história, não apenas como conteúdos a serem conhecidos e decorados mas, sobretudo, como esforço da compreensão de conceitos inerentes a esses conhecimentos que são, em última instância, residência semiótica, lugar onde residem o signos, a linguagem objetivada, as complexas generalizações construídas pelo pensamento humano, objetivadas no conteúdo e que, agora, pelo movimento de apropriação passam a mediar, no pensamento do estudante, operações mais complexas, totalmente novas em relação ao antes, constituindo bases imaginárias indispensáveis à criação. A compreensão do conceito, sublinha Vigotski (1996), modifica substancialmente o pensamento, eleva-o à condição de pensamento teórico, dá a conhecer as leis que regem a realidade, a ordenar o mundo que passa a ser percebido por relações lógicas, possibilita ver o invisível e a compreender que o real não se reduz ao empírico e que a concreticidade das coisas só se mostra, como imagem psíquica, no mergulho que o pensamento faz nas generalizações de um conceito. O que, notadamente, faz da linguagem o elemento central desse processo.

A linguagem é o meio poderoso para analisar e classificar os fenômenos, de regular e
generalizar a realidade. A palavra, portadora do conceito é, [...] a verdadeira teoria do
objeto a que se refere; o geral, nesse caso, serve de lei ao particular. Ao conhecer com a
ajuda das palavras, que são os signos dos conceitos, a realidade concreta, o homem
descobre no mundo que lhe é visível as leis e os nexos que contém (VIGOTSKI, 1996, p. 71).

Esse movimento que é de objetivação e subjetivação ao mesmo tempo, produz imagem psíquica como possibilidade de recombinação para outras imagens psíquicas. Ainda de acordo com Martins (2013, p. 227)

[...] a singularidade da imaginação reside em que, nela, as imagens das experiências prévias se alteram, produzindo outras e novas imagens. Trata-se de uma atividade mental que modifica as conexões já estabelecidas entre imagem e objeto, produzindo outra imagem figurativa. A imagem assim produzida pode operar como modelo psíquico a ser conquistado como produto da atividade orientada por ele, ou seja, por meio desse processo se constrói a imagem antecipada do produto da atividade.

Daí que, um ponto crítico nessa temática é a sua relação com a realidade, ou experiência objetiva, e com a emoção e o sentimento, ou experiência subjetiva que, por sua vez, tem a ver com a imagem psíquica construída pelos sujeitos a partir dos lugares sociais que ocupam no conjunto das relações humanas que vivenciam. Como afirma Lev S. Vigotski (2018, p.21), “[...] é incorreta a visão comum que separa fantasia e realidade como uma linha intransponível." Para demonstrar que a imaginação não é um divertimento ocioso da mente mas uma função vital necessária ao humano, argumenta acera de quatro formas principais de relação entre imaginação e realidade. A primeira consiste em que "[...] toda obra da imaginação constrói-se sempre de elementos tomados da 
realidade e presentes na experiência anterior da pessoa." Donde resulta que a atividade criadora está intimamente relacionada à riqueza da experiência sócio-histórica do indivíduo. A segunda é a articulação entre o produto final da fantasia e um fenômeno complexo da realidade. Nas suas palavras,

Quando, baseando-me em estudos e relatos de historiadores ou aventureiros, componho para mim mesmo, um quadro da grande Revolução Francesa ou do deserto africano, em ambos o quadro resulta da atividade de criação da imaginação. Ela não reproduz o que foi percebido por mim numa experiência anterior, mas cria novas combinações dessa experiência. (o.c., p.24)

O que implica, de acordo com o autor, na subordinação dessa forma à primeira lei citada acima, visto que, sem uma reserva anterior de experiência, resulta impossível a construção de imagens. Uma terceira forma de relação imaginação e realidade é caráter emocional. De acordo com Lev S. Vigotski, esta forma de relação manifesta-se de dois modos. De um lado sentimentos, emoções tendem a se encarnar em imagens conhecidas correspondentes ao sentimento experimentado. De outro, a imaginação influencia o sentimento. Trata-se de um fenômeno chamado por Lev S. Vigotski (2018, p. 29-30) de “[...] lei da realidade emocional da imaginação. [...] A essência dessa lei, é formulada por Ribot do seguinte modo: 'Todas as formas de imaginação criativa contém em si elementos afetivos."'.

Por fim, uma quarta forma dessa relação,

[...] consiste em que a construção da fantasia pode ser algo completamente novo, que nunca aconteceu na experiência de uma pessoa e sem qualquer correspondência com algum objeto realmente existente. No entanto, ao ser externamente encarnada, ao adquirir uma concretude material, essa imaginação "cristalizada", que se fez objeto, começa a existir realmente no mundo e a influir sobre as coisas. (VIGOTSKI, 2018, p.30-31).

Evidencia-se assim o papel estruturante do imaginário ao articular a sensibilidade, da qual o corpo é o natural mediador, e a racionalidade, que opera no registro do simbólico. Articular essas temáticas é fundamental para pensar a questão educacional e as práticas escolares como fatores de desenvolvimento humano.

Na medida em que a educação escolar se define fundamentalmente como via de acesso ao conhecimento produzido pelos homens, um dos componentes básicos do mundo da cultura, entendida como a totalidade das produções humanas, mundo específico do homem onde ele constrói sua existência, essa educação integra o processo de constituição do humano em cada ser. Sob este prisma, a educação escolar é algo, não apenas desejável, mas necessário para o desenvolvimento cultural da pessoa seja ela uma criança, um jovem, um adulto. Isso a transforma num direito fundamental e a coloca no patamar de ser, efetivamente, fator de desenvolvimento 
humano, compreendido como desenvolvimento, em cada indivíduo da espécie, daquilo que é do gênero humano. Em outras palavras e corroborando as teses da escola de Lev S. Vigotski, a educação escolar concorre para o desenvolvimento de funções psicológicas superiores, tipicamente humanas, ou seja, herança da segunda natureza do ser humano: a cultura.

\section{Uma escola lugar do imaginário: algumas conclusões}

É precisamente a atividade criadora do homem que faz dele um ser projetado para o futuro, um ser que contribui para criar e modificar seu presente. Lev S.Vigotski

Neste sentido, “[...]El criterio cualitativo para juzgar los resultados del estudio son la generación de las capacidades, su transferencia a nuevas disciplinas, el carácter consciente, la plasticidad, la capacidad de modificación y otras." (DAVIDOV, MARKOVA, 1987, p. 316). Trata-se, pois, de uma mudança radical no desenho curricular como um todo que sai do foco meramente conteudista tradicional e passa a olhar, conceber e organizar pedagogicamente a aprendizagem como elemento fulcral de desenvolvimento de formas ou modos complexos de operar cognitivamente, típicas do gênero humano, que circulam, por assim dizer, intersubjetivamente pelas relações entre indivíduos e suas trajetórias sócio-hitóricas (sentidos, significados, afetos, emoções, saberes que logram alcançar nesse caminho) e conhecimento escolar. Esse movimento intersubjetivo vai tecendo o humano em cada individuo na medida em que se converte em funções superiores de pensamento intrasubjetivas. Lev S. Vigotski (1995), nos sustenta quando afirma que todas as funções mentais superiores são a essência de relações sociais internalizadas como base estrutural do indivíduo. Esse movimento de internalização, por sua vez, não quer dizer cópia ou reprodução do externo no interno. Antes, concordando com Pino (2003, p.112), [...] a internalização das relações sociais consiste numa conversão das relações físicas entre pessoas em relações semióticas dentro da pessoa." (grifos do autor)

Esse movimento de conversão de relações sociais em elementos de personalidade acontece na vida cotidiana demarcada pela situação social, pelo lugar social que é um lugar histórico, profundamente marcado pelo modo de produção e organização do trabalho que, como procuramos elucidar em parte nesta reflexão, vem se caracterizando por um trabalho alienado, pouco ou nada criador, disciplinado por um modelo de produção que, controversamente, acumula muita riqueza para poucos e muita pobreza para muitos não apenas em termos econômicos mas também, pela desigualdade que produz, inibe fortemente o acesso das camadas mais pobres aos bens simbólicos 
(conhecimento, arte, entre outros.). E se, como nos lembram os autores que nos sustentam, 0 imaginário criativo é uma função superior de pensamento que, como as demais, se constitui em relações sociais e, se a escola se pretende lugar de formação de pessoas criadoras, necessitará indagar-se sobre quem são e de onde vem essas pessoas. Que lugar social ocupa? Que significações alcança construir desde esse lugar? Que elementos desse lugar constituem substrato para imaginar e criar? Como intervir pedagogicamente para fomentar e ampliar imaginação e criação? Que lugar ocupa o imaginário criativo no âmbito do currículo escolar?

Frente a essas indagações nos arriscamos inferir sobre algumas possibilidades para uma outra escola. Uma escola que tenha o desenvolvimento humano como horizonte, concebe o trabalho educativo, ele próprio, como ação criadora, como,

[...] o ato de produzir, direta e intencionalmente, em cada indivíduo singular, a humanidade que é produzida histórica e coletivamente pelo conjunto dos homens. Assim, o objeto da educação diz respeito, de um lado, à identificação dos elementos culturais que precisam se assimilados pelos indivíduos da espécie humana para que eles se tornem humanos e, de outro lado e concomitantemente, à descoberta das formas mais adequadas de atingir esse objetivo.

Sob este enfoque, a escola como tempo-espaço de formação de pessoas criadoras, não abre mão dos conhecimentos historicamente acumulados, já que neles objetivam-se formas humanas de pensamento (abstração, imaginação, criação, teorização...) que são, por assim dizer, insumos fundamentais. Mas também não faz deles meros tópicos de pautas de uma rotina escolar diária, enfadonha e desanimadora. Antes, toma-os como ferramenta mediadora de pensamento teórico, de desenvolvimento da imaginação, da criação, compreendendo que,

As imagens com as quais o ser humano opera não se limitam à reprodução do diretamente percebido. O ser humano pode também ver diante de si em imagens o que não tem percebido diretamente. Também pode ver algo que não existe em absoluto, e também algo que não existe na realidade concreta. Assim, não se pode entender como atividade de reprodução todo processo que transcorre por imagens. Na realidade, toda imagem, em qualquer medida, é tanto reprodução - ainda que distante, mediata e modificada - quanto também transformação do real. Estas duas tendências, que sempre existem em certa unidade, divergem simultaneamente. Enquanto a reprodução é o traço fundamental da memória, é característica da imaginação a transformação do reproduzido. Imaginar algo quer dizer transformá-lo. (RUBINSTEIN 1967, p. 361)

A reflexão de Rubinstein, alimenta pistas importantes para pensar pedagogicamente a formação de pessoas criadoras, na medida em que sinaliza para uma organização pedagógica do processo educativo focada na compreensão de como se desenvolvem, na pessoa, funções como imaginação e criação. Importante observar, a nosso ver, que o ato de reprodução pode ser visto como propulsor de recombinações mentais imaginativas que, por sua vez, podem constituir bases 
importantes de novas criações. Para o que, o processo educativo problematizador e investigativo estará atento.

A formação de pessoas criadoras requer movimentos pedagógicos que mobilizem, pela atividade do trabalho (intelectual ou não), a função imaginativa. O que, desde a perspectiva histórico-cultural, de base materialista histórico-dialética, implica reconhecer que criar e imaginar são atos de pensamento que se constituem a partir de ações e reprodução e criação. Ou seja, reprodução e criação são atributos da imaginação. Logo, no âmbito do processo pedagógico escolar, focado no desenvolvimento humano, constituem tarefas essenciais.

Mais do que nunca, nos parâmetros da abordagem que pauta essa reflexão, a escola segue sendo, sobretudo, lugar de ensinar e de aprender. E, embora ensino e aprendizagem conservem relação de interdependência, ou seja, estejam um em função do outro de forma dialética e dialógica, cada um desses elementos do processo didático conserva características próprias. Ensinar, requer um conjunto de saberes formadores que vai do domínio dos campos teóricos fundantes e suas implicações para o ato de ensinar, ao domínio e criação (imaginação) de estratégias mediadoras dos caminhos cognitivos a serem trilhados por quem aprende. É, de acordo com Freire (1996), é uma especificidade humana que exige rigor metódico, disposição para o diálogo, crença no ser humano, liberdade e autonomia Aprender, por sua vez, constitui um processo fundamental de desenvolvimento humano que, desde a teoria histórico-cultural, quer dizer que a apreensão de conhecimentos escolares é, a um só tempo, elemento de desenvolvimento de funções psicológicas superiores, tipicamente humanas e vivência de processos formativos focados na ampliação do repertório cultural, simbólico, estético e de vivência da civilidade, da solidariedade e do compromisso ético-político. Nesta perspectiva, tendo em vista uma educação alicerçada a partir de princípios de formação do imaginário criativo e de pessoas criadoras, andam amalgamadas a ciência, a justiça e a arte.

\section{REFERÊNCIAS}

DAVÍDOV, Vasili. V. Análisis de los principios didácticos de la escuela tradicional y posibles principios de enseñanza en el futuro próximo. In: SHUARE, M. (Org.). La Psicologia evolutiva y pedagógica em la URSS: antologia. Moscou: Progeso, 1987. p. 143-142.

DAVIDOV.Vasili. MARKOVA, A. La Concepcion De La Actividad De Estudio De Los Escolares. In: SHUARE, M. (Org.). La Psicologia evolutiva y pedagógica em la URSS: antologia. Moscou: Progeso, 1987. P. $316-336$. 
FREIRE, Paulo. Pedagogia da autonomia: saberes necessários à prática educativa. São Paulo: Paz e Terra,1996.

MAHEIRIE, Kátia. Subjetividade, imaginação e temporalidade: a atividade criadora em objetivações discursivas. In.: DA ROS, Silvia Z.; MAHEIRIE, Kátia; ZANELLA, Andréa. Relações Estéticas, atividade criadora e imaginação. Florianópolis: NUP/CED/UFSC, 2006.

MARTINS, Ligia. O desenvolvimento do Psiquismo e a educação escolar. São Paulo: Autores e Associados, 2013.

MARX, Karl. Manuscritos de 1844, trad. fr. Paris, Éditions Sociales, 1972.

MARX, Karl. O Capital: crítica da economia política. 2.ed. São Paulo: Nova Cultural, 1986.

MARX, Karl. ENGELS, F. A Ideologia Alemã (Feurbach), 9ạ. ed. São Paulo: Hucitec, 1993

MARX, Karl. O dezoito brumário de Louis Bonaparte. 3. ed. São Paulo: Centauro, 2003.

MOLON, Susana I. Subjetividade, sujeito e atividade criadora: questões para a formação continuada de educadores (as) na abordagem sócio-histórica. In.: DA ROS, Silvia Z.; MAHEIRIE, Kátia; ZANELLA, Andréa. Relações Estéticas, atividade criadora e imaginação. Florianópolis: NUP/CED/UFSC, 2006.

MOZZER, Geisa N. S.; BORGES, Fabrícia T. A criatividade infantil na perspectiva de Lev Vigotski. In.:Revista Inter Ação, 33(2), 297-316, 2008. Disponível em: https://www.revistas.ufg.br/interacao/article/view/5269 . Acessado em 11 de fevereiro de 2019.

OLIVEIRA, Artur B. F.; LIMA, Ana I.B. Vigotski e os Processos Criativos de

Professores ante a Realidade Atual. In.: Educação \& Realidade, Porto Alegre, v. 42, n. 4, p. 1399-1419, out./dez. 2017

PINO, Angel. As marcas do humano: às origens da constituição cultural da criança na perspectiva de Lev. S. Vigotski. São Paulo: Cortez, 2005.

PINO, Angel. A produção imaginária e a formação do sentido estético. Reflexões úteis para uma educação humana. Pro-Posições, Campinas, v. 17, n. 2(50), p. 47-69, ago. 2006.

PINO, Angel. Imaginação e produção imaginária: reflexões em educação. In.: DA ROS, Silvia Z.; MAHEIRIE, Kátia; ZANELLA, Andréa. Relações Estéticas, atividade criadora e imaginação. Florianópolis: NUP/CED/UFSC, 2006.

RUBINSTEIN. Sergey Leonidovich. Princípios de psicologia geral. México: Grijalbo, 1967.

SAVIANI, Dermeval. Pedagogia Histórico-crítica: primeiras aproximações. 8aed., Campinas (SP): Autors e Associados, 2003.

SCHLINDWEIN, Luciane M. Formação de professoras, memória e imaginação. In.: DA ROS, Silvia Z.; MAHEIRIE, Kátia; ZANELLA, Andréa. Relações Estéticas, atividade criadora e imaginação. Florianópolis: NUP/CED/UFSC, 2006.

VIGOTSKI, Lev S.. Obras Escogidas. Tomo III. Madrid: Visor, 1995

VIGOTSKI, Lev S. Obras Escogidas. Tomo IV. Madrid: Visor, 1996

VIGOTSKI, Lev S. Imaginação e criação na infância. Trad. Zóia Prestes e Elizabeth Tunes. São Paulo: Expressão Popular,2018.

ZANELLA, Andréa V. "Pode até ser flor se flor parece a quem o diga": reflexões sobre educação e estética e o processo de constituição do sujeito. In.: DA ROS, Silvia Z.; MAHEIRIE, Kátia; ZANELLA, Andréa. Relações Estéticas, atividade criadora e imaginação. Florianópolis: NUP/CED/UFSC, 2006. 


\section{SOBRE A AUTORA}

\section{Solange Maria Alves}

Doutora em Educação pela USP. Atua como professora no curso de Pedagogia e no PPGE da Universidade Federal da Fronteira Sul -UFFS. Preside o grupo de pesquisa GEPEVI - Grupo de Estudos e Pesquisas Escola de Vigotski e é membro do GPETE - Grupo de Pesquisa Espaço-Tempo e Educação na mesma instituição. Emails: solange.alves@uffs.edu.br esolangesol13@gmail.com

ORCID: https://orcid.org/0000-0002-5222-6066

Recebido em: 04/07/2019.

Aprovado em: 09/01/2020.

Publicado em: 16/02/2020. 